\title{
Case Study: Expanding Management Foundations
}

\author{
https://doi.org/10.3991/ijac.v12i2.11413
}

\author{
Alan Todd $(\bowtie)$ \\ Corp/U, Philadelphia, Pennsylvania, USA \\ atodd@corpu.com
}

\section{Background}

Managers serve as change agents, at least that is how Merck sees them. Merck is a global healthcare company that delivers innovative health solutions through its prescription medicines, vaccines, biologic therapies, and animal health products. Merck's Leadership Development team was looking to capitalize on an opportunity to reshape its existing Management Foundations Program, initially developed a decade ago. This Program is designed to rapidly upskill newly-minted people managers to drive business [through improved strategic awareness], better understand and develop the self [biases and resilience], and lead others [coaching, performance, goals, leading teams] within the first six months in their new role.

The company overall was introducing and implementing a new enterprise-wide strategy as well as a new Performance Management process, making the timing right and necessary to help managers execute, innovate, and adapt.

Previously, Merck's learning program was primarily classroom-based/instructorled training. This type of delivery was extremely expensive, and required new managers to expend numerous hours away their from work. In addition, the travel requirements and limited number of available offerings sometimes resulted in new managers not having an opportunity to take advantage of the program. This led Merck to partner with Corp/U to develop a new training program that would not only help engage more leaders, but help drive change.

The Corp/U Organizational Learning System (OLS) helps build organizational capabilities, drive change, and deliver value to customers through innovation. Integrated with social technology, a network of experts, and analytics, OLS is designed build new capacity of entire leadership teams in a way that is fun, collaborative, and tailored to business needs. Corp/U's Organizational Learning System takes a very human approach to digital experiences, and by doing so, helps organizations create more impact in less time.

Merck challenged itself to expand the Management Foundations curriculum in order to better meet the needs of the company's new strategy, efficiently and effectively develop new managers, serve as an input to their overall change management approach, and demonstrate a clear return-on-investment. 


\section{Design Leadership Program}

Merck was interested in effectively onboarding newly-minted managers to drive organizational strategic goals, build capabilities necessary for success in the role, and build greater speed to effective leadership in an ongoing, resource-driven community of practice by connecting new managers, building networks across divisions and regions, and sharing best practices through a collaborative approach while learning.

Most specifically, Merck focused on progress toward the following three goals for managers with tenure of less than six months:

1. A change in perspective. Merck wanted to create a program that broadened the mindset of new managers as they developed them from individual contributor to people-manager who would also serve as change agents in executing on the organization's new strategy. Through Corp/U's platform, Figure 1 shows how Merck was able to measure managers' capabilities for serving as change agents by identifying who had the following key qualities: the interest (commitment, advocacy), ability (understanding) and reach (influence, authority) to champion and implement change.

2. An emphasis on strategic knowledge. Merck required a program that would ensure the development of skills and behaviors that would effectively execute on and support a new strategy. Corp/U's analysis (see Figure 2) showed that commitment to apply learned organizational strategy knowledge and skills to lead people was very high.

3. An agile learning offering. Merck desired a learning program that would foster growth, while also being simple to modify in a virtual format. Flexibility to alter content was necessary, since the new strategy was being delivered while people were being developed to execute on each component.

\section{Change Ambassadors}

\begin{tabular}{l|c|c|c|c|c|}
\hline Name & Influence & Authority & Advocacy & Commitment & Understanding \\
\hline Ana Maria Chaparro Ruiz & & & & & \\
\hline Hector Ramos & & & & & \\
\hline Kristin Fitzgerald & & & & & \\
\hline Tricia Frantz & & 0 & & & \\
\hline Daun Bevacqua & & & & & \\
\hline Jeroen Mertens & & 0 & & & 0 \\
\hline Top 5\% \\
Top $10 \%$ \\
Top 25\%
\end{tabular}

Fig. 1. 


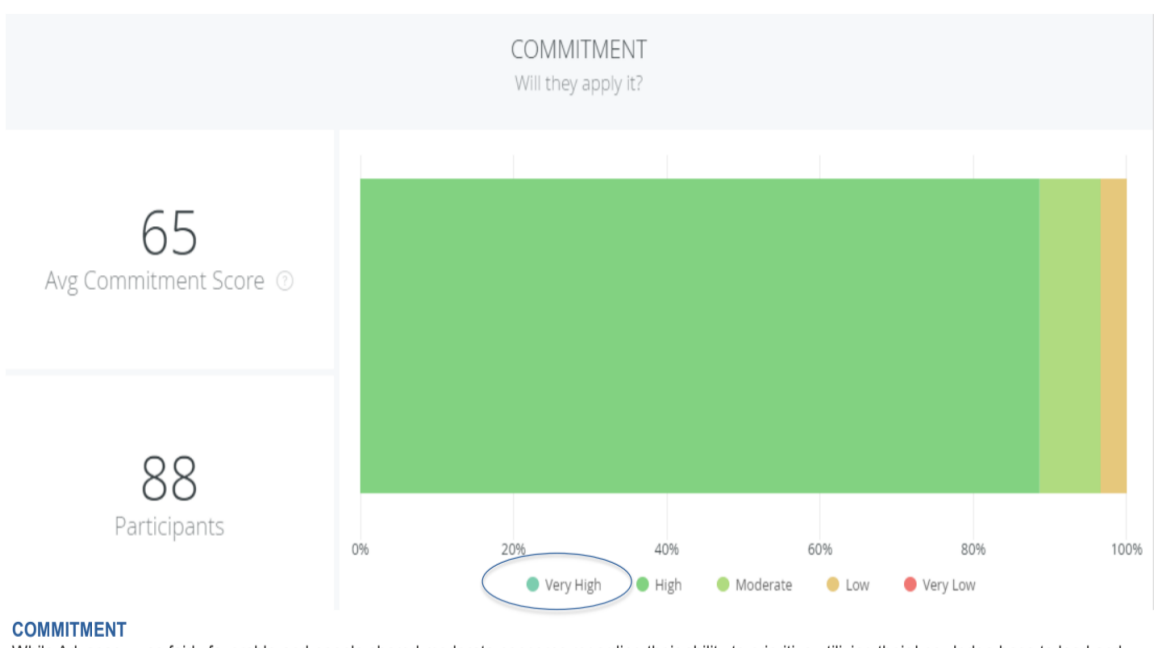

While Advocacy was fairly favorable and people shared moderate concerns regarding their ability to prioritize utilizing their knowledge base to lead and While Advocacy was fairly favorable and people shared moderate concerns regarding their ability to prom
develop talent within the organization , their commitment is applying the skills they learned is very high.

Fig. 2.

Finally, an overall goal for the Merck team was to improve demonstrable returnon-investment by showing direct and indirect value using data analytics. The Corp/ $\mathrm{U}$ program provides superior access to feedback and analytics to show the impact of learning.

\section{$3 \quad$ Program Delivery}

Delivery was a critical decision for this program as the target audience has a very busy schedule and is constantly absorbing a variety of cultural, technical, and commercial changes. The original course was designed as nine weeks of content spread over four months and focused on critical/essential content to the program (see Figure 3).

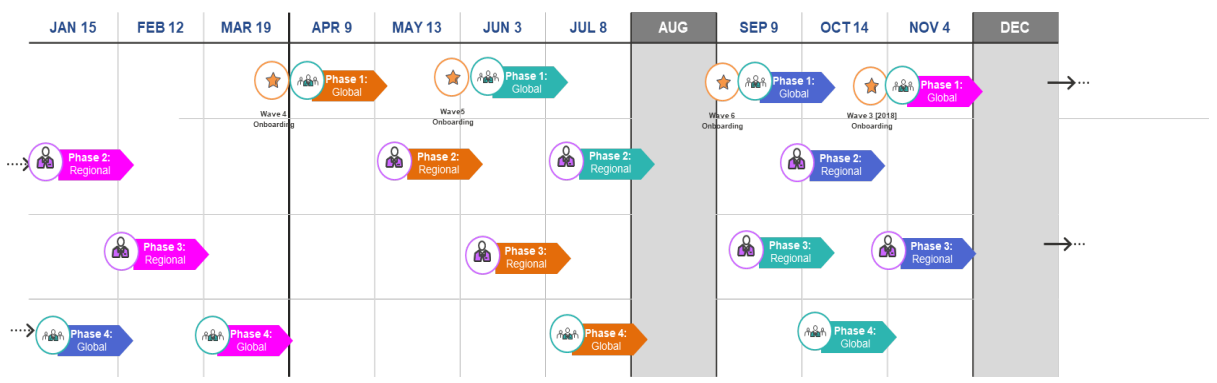

Fig. 3. 
Figure 4 shows an example of one week's worth of content.

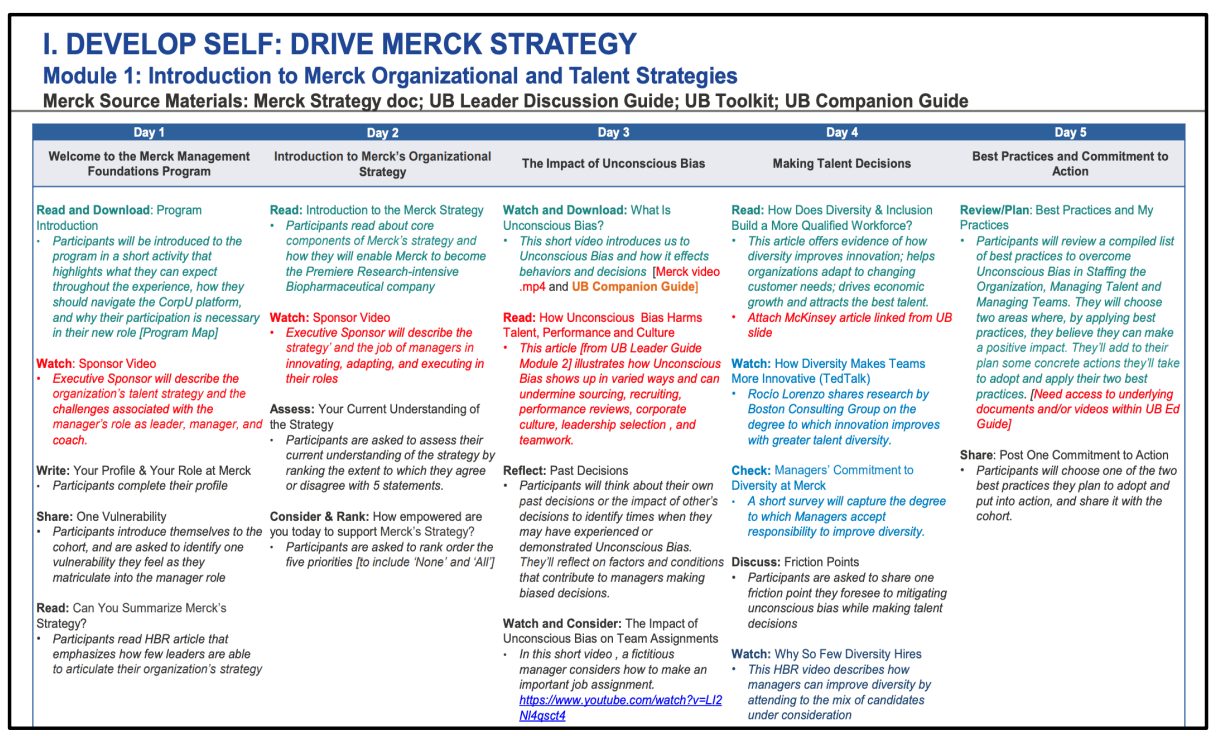

Fig. 4.

Shortly after implementation, NPS data captured on the Corp/U platform indicated that participant satisfaction was trending low as the result of content-heavy activities. In effect, managers were struggling with the time required to complete the sprint. Merck and Corp/U quickly pivoted and worked together to reduce the volume of content by eliminating some content, while assigning a portion of content as "optional". By taking these actions, the Net Promoter Score dramatically improved by 30 points.

With 11,700 managers around the globe and 1,200 new managers hired annually, communication must be clear and consistent. By using Corp/U's virtual platform Merck established a new standard for communication that builds in accountability and offers ongoing reminders that guide learners toward completion. Further, Merck was able to articulate the purpose of the program, the important role managers play, and why this learning experience mattered. The result has been higher levels of engagement, and the surfacing of actionable insights not otherwise available to the organization, e.g. identified need for clarity in strategic sourcing for diverse talent pools. To date, 1,300 managers have matriculated from the program with clear organizational benefits and high participant satisfaction.

\section{$4 \quad$ Results}

For their classroom program, Merck tracked feedback via a survey tool which only provided for a one-way feedback channel. For the virtual program, Merck was able to take advantage of a portfolio of tools offered by Corp/U's platform to evaluate impact across the organization. 
A participant's first name, last name, and email address initiate a unique user ID which allows the following types of data analysis to be conducted (see Figure 5): quantitative, qualitative, topic modeling, proprietary algorithms, and network analysis.

All metrics are tracked in support of the desired business outcomes.

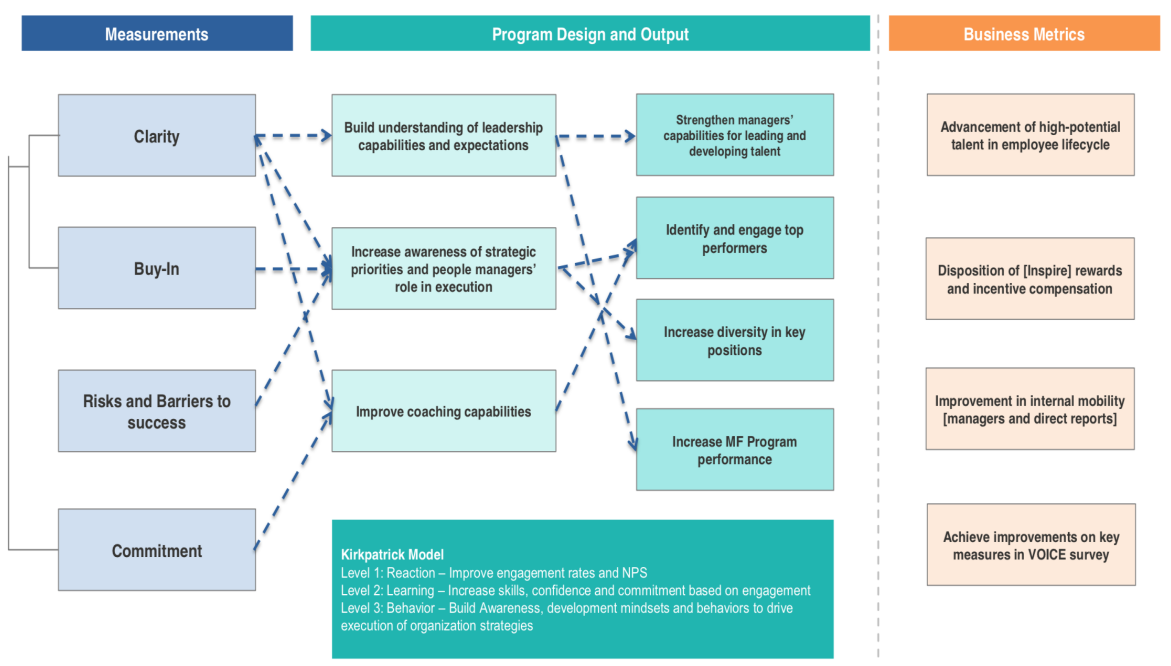

Fig. 5.

Merck has tracked the four business metrics using the following Corp/U data collection tools and has seen a notable change:

1. Advancement of high-potential talent in the employee lifecycle

2. Disposition of rewards and incentive compensation

3. Improvement in internal mobility

4. Achieve improvement on key measure in Merck's VOICE survey

The program launched on June 1, 2018, and the pilot results were reviewed in November 2018. The program is expected to continue running year-over-year; we'll be doing a review of cohorts 2 and 3 in late April 2019; however, in advance of this data, Merck has witnessed progress in each of the four areas.

Merck is realizing immense value in the Virtual Management Foundations Program as a method to scale and evolve how they communicate strategy and capabilities to their important manager population. Several divisions and geographies are reviewing the program content and considering how they might tailor the program to their particular audience, enhancing the potential reach of the Virtual Management Foundations Program. 


\section{$5 \quad$ Author}

Alan Todd is CEO of CorpU. A pioneer in the field of corporate learning, Alan has served as Chairman, CEO and co-founder of KnowledgePlanet, a company that helped launch the online learning revolution. The company grew to serve millions of people in over 150 countries and amassed more than $\$ 150$ million in value.

Alan was named Inc. Magazine / Ernst \& Young Entrepreneur of the Year for High Technology in the late ' 90 s. More recently, he was appointed by Pennsylvania Governor Tom Corbett to the Higher Education Commission, charged with improving college access and affordability for commonwealth residents.

Alan is a founding member and trustee of Harrisburg University of Science and Technology, the first private non-profit university in Pennsylvania established in over 100 years. He also serves as a Wharton entrepreneur-in-residence and education entrepreneurship adviser at the Penn Graduate School of Education.

He is a member of the Education Innovation Advisory Board at Arizona State University and a member of the board of advisors of Penn NEST - Networking Education Entrepreneurs for Social Transformation - based at the University of Pennsylvania. He has also been a trustee at Dickinson College, on the Business Advisory Board at Pennsylvania State University and Messiah College, and has acted as an education advisor to the Saudi royal family.

Alan completed his doctoral coursework and holds a master's degree from The University of Pennsylvania.

Article submitted 2019-07-31. Resubmitted 2019-09-08. Final acceptance 2019-09-08. Final version published as submitted by the authors. 